\title{
Small Bowel Lymphangio- ma - A Rare Cause of Small Bowel Bleeding
}

\begin{abstract}
Lymphangiomas represent benign embryonic vascula malformations of the lymphatic architecture. A symptomatic small bowel lymphangioma in an adult is a rare finding. Here we present a case of a 93 year-old male who had a 3-month history of intermittent melena. After an unrevealing upper endoscopy, colonoscopy was significant for blood emanating from the ileo-cecal valve. Video capsule endoscopy was significant for bright blood and clots in jejunum. Small bowel enteroscopy demonstrated multiple jejunal sub-mucosal masses. The bleeding lesion was biopsied and then successfully treated with Argon Plasma Coagulation (APC). Histopathology was consistent with a lymphangioma.
\end{abstract}

\section{Introduction}

Lymphangiomas are believed to be a benign embryonic vascular malformation of the lymphatic architecture. These benign tumors are primarily seen in children located in the head, neck and axillary region. Infrequently, intra-abdominal lymphangiomas are diagnosed in adults, primarily in the mesentery [1]. Lymphangiomas exist in 3 forms: circumscriptum, cavernous and cystic. A circumscriptum (also known as capillary) lymphangioma is defined by small thinwalled lymphatics in the superficial dermis [2]. The cystic type contains serous, chylous or bloody fluid with no connection to adjacent lymphatics; while the cavernous sub-type is characterized by larger dilated lymphatic channels [2]. The cavernous type can be fast growing and is the most likely subtype to cause gastrointestinal bleeding. Symptomatic small bowel lymphangiomas are a very rare finding in adults and less than 20 cases have been described in the literature to date [2-4].

\section{Case Presentation}

A 93 year-old male with recently diagnosed atrial fibrillation and initiation of Rivaroxaban presented with a 3-month history of intermittent melena and iron deficiency anemia. He presented to the emergency room with hemoglobin of $7.0 \mathrm{~g} / \mathrm{dl}$ (normal range: 13.0-7.5 $\mathrm{g} / \mathrm{dl}$ ). An urgent upper endoscopy was performed and was found to be normal. Colonoscopy was significant for melena throughout the colon. Blood was noted to be emanating from the ileo-colonic valve but a definitive source was not identified. The patient then underwent capsule endoscopy, which demonstrated bright red blood with clots in the jejunum. During his course at the outside hospital, he required 10 units of packed Red Blood Cells (pRBCs) over 5 days. A video capsule endoscopy revealed bright red blood and clots in the jejunum, but the exact source of bleeding was unclear.

The patient had ongoing bleeding, and he was transferred to our tertiary care center. On presentation, his hemoglobin was $6.9 \mathrm{~g} / \mathrm{dl}$ with an MCV $=90.1 \mathrm{fL}$ (normal range MCV 81.3-96.4 fL). A push enteroscopy was performed with a pediatric colonoscopeon arrival.

\section{Journal of}

Clinical \& Medical Case Reports

\section{Cassandra DL Fritz ${ }^{1}$ and Gabriel Lang ${ }^{2 *}$}

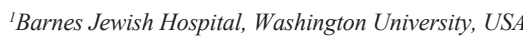
${ }^{2}$ Division of Gastroenterology, Washington University, USA

Address for Correspondence:

Gabriel Lang, Division of Gastroenterology, Washington University in St. Louis 660 S. Euclid Avenue, Campus Box 8124, USA, E-mail: glang@dom.wustl.edu

Submission: 24 January, 2018

Accepted: 17, February, 2018

Published: 23 February, 2018

Copyright: (c) 2018 Fritz CDL, et al. This is an open access article distributed under the Creative Commons Attribution License, which permits unrestricted use, distribution, and reproduction in any medium, provided the original work is properly cited.

It revealed multiple jejunal sub-mucosal masses, the largest of which measured $2.5 \mathrm{~cm}$ in diameter and was actively bleeding (Figure 1). The bleeding lesion was biopsied and hemostasis was successfully achieved with use of argon plasma coagulation (APC-effect 2, flow $1.8 \mathrm{~L} / \mathrm{min}$ and $20 \mathrm{~W}$ ) and hemostatic clips (Figure 2). Histopathology revealed irregular dilated vascular and lymphatic spaces with intraluminal thrombus consistent with lymphangioma (Figure 3). The patient's bleeding resolved and the patient was discharged home with further wishes for only comfort care.

\section{Discussion}

Among patients who present with gastrointestinal bleeding, 5\% will not have a source identified on upper or lower endoscopy [5]. Capsule endoscopy has demonstrated significant diagnostic utility for Obscure Gastrointestinal Bleeding (OGIB) [6]. Capsule endoscopy has also been shown to have an increased yield in older patients [7]. Furthermore, capsule endoscopy prior to small bowel enteroscopy has demonstrated a superior diagnostic yield when compared to just initial push enteroscopy [8]. Similar to the case presented here, capsule endoscopy allowed prognostication for the utility of push

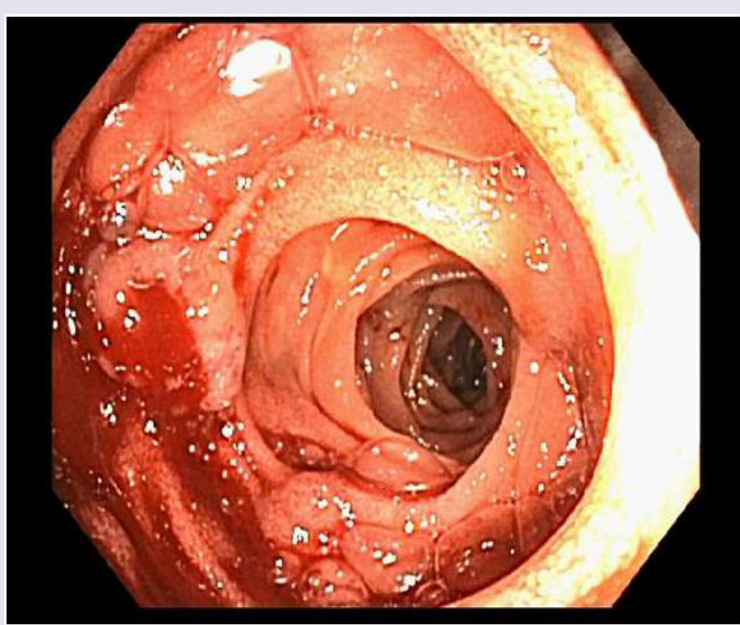

Figure 1: Jejunal sub-mucosal mass with active bleeding 


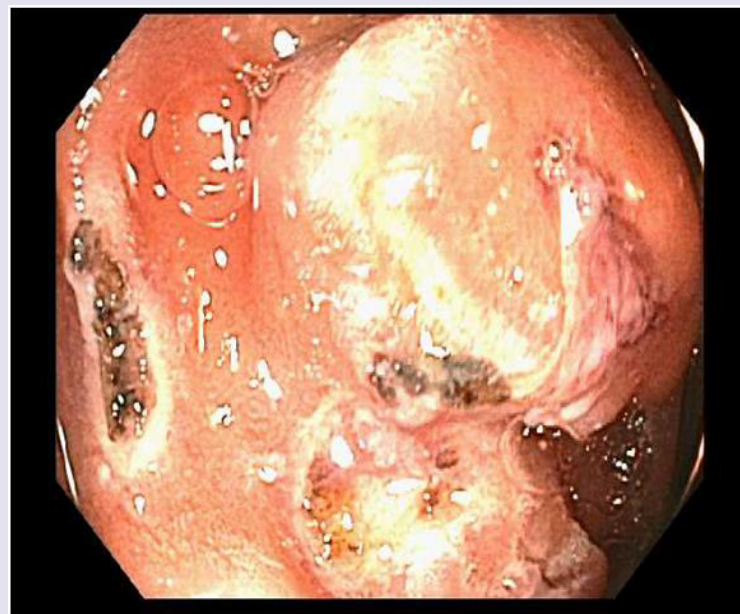

Figure 2: Jejunal sub-mucosal mass after APC treatment.

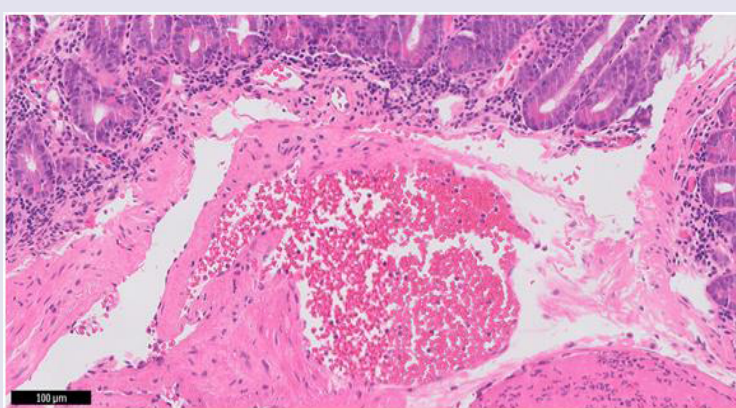

Figure 3: Histopathology at 10x power. Thrombosis within dilated vascular space.

enteroscopy.

Lymphangiomas comprise approximately $3 \%$ of small bowel tumors [9]. Although typically asymptomatic, small bowel lymphangiomas can cause a number of conditions including: GI bleeding, anemia, abdominal pain, volvulus and obstruction [10]. The cavernous subtype is the primary type to cause GI bleeding due to its propensity for ulceration, spontaneous bleeding, and surface erosion [2]. Surgical removal is the definitive treatment for symptomatic lymphangiomas [10]. Yet endoscopic treatment modalities have been utilized for symptomatic patients, specifically hemostatic clips and epinephrine injection [11]. Unfortunately, re-bleeding with these modalities is common. Push enteroscopy is an established and effective tool for small bowel bleeding [9]. Specifically, its diagnostic yield is as high as $56 \%$ and has been shown to decrease transfusion requirements [6]. Small bowel enteroscopy with APC treatment can successfully palliate bleeding from small bowel lymphangiomas in patients who are not surgical candidates with good long-term success.

Capsule endoscopy and small bowel enteroscopyare pivotal diagnostic and therapeutic interventions for small bowel OGIB. Although lymphangiomas are a rare cause of OGIB, if encountered, clinicians should be aware of the therapeutic utility of small bowel enteroscopy with APC for patients who are poor surgical candidates.

\section{References}

1. Allen JG, Riall TS, Cameron JL, Askin FB, Hruban RH, et al. (2006) Abdominal lymphangiomas in adults. J Gastrointest Surg 10: 746-751.

2. Tang SJ, Bhaijee F (2014) Small bowel lymphangioma. Video J Encyclopedia GI Endoscopy 1: 663-665.

3. Jung SW, Cha JM, Lee JI, Joo KR, Choe JW, et al. (2010) A case report with lymphangiomatosis of the colon. J Korean Med Sci 25:155-158.

4. Tseng CM, Su YC, Tai CM (2016) An unusual cause of obscure gastrointestinal bleeding. Gastroenterology 150: e9-e10.

5. Pennazio M, Eisen G, Goldfarb N (2005) ICCE consensus for obscure gastrointestinal bleeding. Endoscopy 37: 1046-1050.

6. ASGE Standards of Practice Committee, Fisher L, Lee Krinsky M, Anderson MA, Appalaneni V, et al. (2010) The role of endoscopy in the management of obscure GI bleeding. Gastrointest Endosc 72: 471-479.

7. Scaglione 1, Russo F, Franco MR, Sarracco P, Pietrini L, et al. (2011) Age and video capsule endoscopy in obscure gastrointestinal bleeding: a prospective study on hospitalized patients. Dig Dis Sci 56: 1188-1193.

8. Segarajasingam DS, Hanley SC, Barkun AN, Waschke KA, Burtin P, et al. (2015) Randomized controlled trial comparing outcomes of video capsule endoscopy with push enteroscopy in obscure gastrointestinal bleeding. Can J Gastroenterol Hepatol 29: 85-90.

9. Cai JT, Chen JM, Zhang XM, Chen Y, Wei SM, et al. (2012) Gastrointestinal Small bowel lymphangioma diagnosed by single-balloon enteroscopy. J Gastroenterol Hepatol 27: 1407-1407

10. Morris-Stiff G, Falk GA, El-Hayek K, Vargo J, Bronner M, et al. (2011) Jejunal cavernous lymphangioma. BMJ Case Rep 2011: bcr0320114022.

11. Lin RY, Zou H, Chen TZ, Wu W, Wang JH, et al. (2014) Abdomina lymphangiomatosis in a 38-year-old female: Case report and literature review. World J Gastroenterol 20: 8320-8324. 